\title{
The Effects of Ovariectomy and Estrogen Replacement on trkA and Choline Acetyltransferase mRNA Expression in the Basal Forebrain of the Adult Female Sprague-Dawley Rat
}

\author{
Pamela J. McMillan, Cherie A. Singer, and Daniel M. Dorsa \\ Departments of Pharmacology and Psychiatry and Behavioral Sciences, University of Washington, \\ Seattle, Washington 98195
}

Cognitive deficits associated with aging and with neurodegenerative diseases such as Alzheimer's disease have been attributed to degeneration of cholinergic neurons in the basal forebrain. Estrogen is known to provide trophic support to cholinergic neurons, although the mechanisms underlying the actions of estrogen have yet to be determined. Because cholinergic neurons require neurotrophic growth factors for their survival, it is possible that the trophic effects of estrogen on basal forebrain systems are caused by enhanced expression of neurotrophins or their receptors. To begin to examine this hypothesis, we used in situ hybridization analysis to determine the effects of ovariectomy (ovx) and estrogen replacement on trkA mRNA levels in the rat basal forebrain. Ten days of estrogen deprivation after ovx resulted in significant decreases in trkA mRNA levels in the horizontal limb of the diagonal band of
Broca and the nucleus basalis of Meynert. Short-term estrogen replacement therapy restored trkA mRNA expression to a level comparable with ovary-intact animals. No changes in trkA mRNA levels were observed in the vertical limb of the diagonal band of Broca after ovx or estrogen replacement. To assess the functional status of cholinergic neurons in the absence and presence of estrogen, the effects of ovx and estrogen replacement on ChAT mRNA levels were also examined and found to reflect the changes observed in trkA mRNA expression. These studies suggest that the trophic effects of estrogen on basal forebrain cholinergic systems may be mediated, in part, through the signaling of neurotrophic growth factors through their receptors.

Key words: estrogen; neurotrophins; trkA; ChAT; cholinergic neurons; basal forebrain
Neurotrophins are responsible for the development and maintenance of basal forebrain cholinergic neurons. Members of the neurotrophin family include nerve growth factor (NGF), brainderived neurotrophic factor (BDNF), and neurotrophins 3 and 4/5 (NT-3 and NT-4/5). Neurotrophins transduce their signals by binding to members of the trk receptor tyrosine kinase family, consisting of trkA (NGF), trkB (BDNF and NT-4/5), and trkC (NT-3). Binding to the trk receptors initiates a cascade of signal transduction events resulting in the stimulation of mechanisms necessary for survival, neurite growth, and functions related to transmitter production and release.

Cholinergic neurons of the basal forebrain, including those in the nucleus basalis of Meynert (nBM) and the vertical and horizontal limbs of the diagonal band of Broca (VDB and HDB, respectively), project to the cortex and hippocampus and have been implicated in learning and memory. Loss of cholinergic neurons may be partially responsible for the cognitive decline that is associated with aging and with neurodegenerative diseases such as Alzheimer's disease (Luine et al., 1986; Decker and McGaugh, 1991). Studies indicate that administration of exogenous NGF can reverse cholinergic degeneration and improve performance in

Received Oct. 18, 1995; revised Dec. 7, 1995; accepted Dec. 12, 1995.

This work was supported by U.S. Public Health Service Grant AG05136 and National Institutes of Health Grant NS2031] (D.M.D.), and by Reproductive Biology Training Grant HDO7453-01 (P.J.M.). We thank Dr. Mark Bothwell (University of Washington) for the trkA cDNA and Dr. Hidemi Misawa (Tokyo Metropolitan Institute for Neuroscience) for the ChAT cDNA. We also thank Jennifer Tullis for excellent technical assistance.

Correspondence should be addressed to Dr. Pamela J. McMillan, Department of Pharmacology, P.O. Box 356560, University of Washington, Seattle, WA 98195.

Copyright $\odot 1996$ Society for Neuroscience $0270-6474 / 96 / 161860-06 \$ 05.00 / 0$ memory-dependent tasks (Fischer et al., 1987; Dekker et al., 1992; Lapchak et al., 1993). However, because of its inability to cross the blood-brain barrier, an effective means of delivering NGF to target cells in the brain has been difficult to develop. Therefore, alternative mechanisms that promote the survival of cholinergic neurons must be studied.

Studies indicate that estrogen may modulate cholinergic transmission in the brain. For example, ovariectomy (ovx) of female rats results in a decrease in high-affinity choline uptake, choline acetyltransferase (ChAT) activity, and ChAT mRNA levels, an effect that can be reversed by treatment with estrogen (Luine et al., 1975; Luine and McEwen, 1983; Luine et al., 1986; Gibbs et al., 1994; Singh et al., 1994). In addition, estrogen has been shown to influence the expression of the neurotrophins and their receptors. Singh et al. (1994) have reported decreased levels of NGF and BDNF mRNAs in the rat cortex and hippocampus in response to ovx. Expression of these mRNAs increases after estrogen replacement (Singh et al., 1993, 1995). Estrogen treatment also has been shown to enhance trkA rcceptor mRNA cxpression in the rat dorsal root ganglion (DRG) and in PC12 cells (Sohrabji et al., 1994a,b). Because a number of cholinergic neurons in the basal forebrain seem to coexpress the trkA receptor and the estrogen receptor (Toran Allerand et al., 1992), it is possible that estrogen may influence cholinergic function by altering trkA expression. This study begins to examine the hypothesis that the trophic effects of estrogen on basal forebrain systems are partially mediated through the signaling of neurotrophins through their receptors. To test this hypothesis, in situ hybridization studies were used to determine the effects of short-term ovx and estrogen 
replacement on trkA and ChAT mRNA levels in the basal forebrain.

\section{MATERIALS AND METHODS}

Animals. Adult (3-month-old) female Sprague-Dawley rats (Simonson Laboratory, Gilroy, CA) were maintained on a $12 \mathrm{hr}$ light/dark cycle with unlimited access to food and water according to the guidelines set in the National Institutes of Health Guide for the Care and Use of Laboratory Animals. All procedures performed on animals were approved by the VAMC Animal Care Committee before the initiation of this study. Two-thirds of the rats underwent bilateral ovx under Metafane anesthesia, and the remaining rats were left intact. One week after surgery, half of the rats in the ovx group were injected subcutaneously with estradiol benzoate $(10 \mu \mathrm{g} / \mathrm{d}$ in $0.1 \mathrm{ml}$ of sesame oil) for $3 \mathrm{~d}$, whereas the remaining rats were injected with vehicle. Twenty-four hours after the final injection, all rats were killed by decapitation. Brains were removed, rapidly frozen on dry ice, and stored at $-80^{\circ} \mathrm{C}$ until sectioning. Twenty micrometer coronal sections were cut on a cryostat and mounted on RNase-free gelatin-coated slides and stored at $-80^{\circ} \mathrm{C}$.

Probes. The trkA probe used in this study is a $582 \mathrm{bp}$ fragment containing the $5^{\prime}$-untranslated region (UTR) and the first $521 \mathrm{bp}$ of the coding region of a rat trkA cDNA isolated from PC12 cells (a gift from Dr. Mark Bothwell, University of Washington, Seattle, WA) subcloned into the $X b a \mathrm{I}$ and HindIII sites of the pGEM7Z plasmid. For transcription of the antisense (complementary) riboprobe, the plasmid was linearized with $X b a I$ and transcribed with SP6 RNA polymerase. The ChAT probe used in this study is a $532 \mathrm{bp}$ fragment from the 3'-UTR of a rat spinal cord cDNA (a gift from Dr. Hidemi Misawa, Tokyo Metropolitan Institute for Neuroscience, Tokyo, Japan) subcloned into the EcoRI and Bst XI sites of the pGEM7Z plasmid. This cDNA has been shown previously to cross-react with brain-derived ChAT (Ishii et al., 1990). For transcription of the ChAT antisense riboprobe, the plasmid was linearized with $N$ sil and transcribed with T3 RNA polymerase. Transcription reactions were carried out using the Riboprobe Gemini System (Promega, Madison, WI) according to the manufacturer's instructions in the presence of $10 \mu \mathrm{M}\left[{ }^{35}\right.$ S Juridine triphosphate. Riboprobes were purified by phenol/chloroform extraction and ethanol precipitation and resuspended in TED buffer $(0.1 \mathrm{M}$ Tris, $1 \mathrm{mM}$ EDTA, and $0.1 \mathrm{M}$ dithiothreitol). The specificity of these probes was determined previously by hybridization with ${ }^{35} \mathrm{~S}$-labeled sense (control) riboprobes (data not shown).

Preparation of tissue and in situ hybridization. Tissue preparation and in situ hybridization procedures were performed as described previously (Shughrue et al., 1992). Briefly, section-mounted slides were post-fixed in $4 \%$ paraformaldehyde, treated with acetic anhydride $(0.25 \%$ in $0.1 \mathrm{M}$ triethanolamine), and delipidated and dehydrated through a graded series of ethanol and chloroform. Section-mounted slides were hybridized overnight under saturating conditions with ${ }^{35} \mathrm{~S}$-labeled antisense trkA or ChAT riboprobes $(0.1 \mathrm{pmol} / \mathrm{slide})$ at $58^{\circ} \mathrm{C}$ (trkA) or $68^{\circ} \mathrm{C}(\mathrm{ChAT})$. After hybridization, slides were washed in $1 \times \mathrm{SSC}(150 \mathrm{~mm} \mathrm{NaCl}$ and $15 \mathrm{~mm}$ Na-citrate) at room temperature for $30 \mathrm{~min}$, treated with RNase buffer (10 mM Tris, $\mathrm{pH} 8,0.5 \mathrm{M} \mathrm{NaCl}, 1 \mathrm{~mm}$ EDTA, $\mathrm{pH}$ 8, and $20 \mu \mathrm{g} / \mathrm{ml}$ RNase A) at $37^{\circ} \mathrm{C}$ for $30 \mathrm{~min}$, and rinsed in $1 \times \mathrm{SSC}$ at room temperature for 30 $\mathrm{min}$. Slides were then washed for $1 \mathrm{hr}$ in three changes of $0.1 \times \mathrm{SSC}$ at $65^{\circ} \mathrm{C}$ (trkA) or $75^{\circ} \mathrm{C}$ (ChAT) followed by a final wash in the same solution at room temperature. Slides were then dehydrated through a graded series of alcohols containing ammonium acetate and air-dried. Finally, section-mounted slides were dipped in Kodak NTB2 Nuclear Track emulsion (diluted $1: 1$ in $0.6 \mathrm{M}$ ammonium acetate) and stored in dry, light-tight boxes at $4^{\circ} \mathrm{C}$ for 3 weeks (trkA) or $10 \mathrm{~d}$ (ChAT). The slides were photographically processed, stained with cresyl violet acetate, and mounted with coverslips.

Data analysis. Analysis of grain counting was performed using a MicroComputer Imaging Device (Imaging Research, St. Catherines, Ontario, Canada). The relative levels of trkA and ChAT mRNAs in the $\mathrm{nBM}, \mathrm{HDB}$, and VDB (see Fig. 1) were compared in intact, ovx, and estrogen-replaced (ovx $+E$ ) rats. Before data were analyzed, a double threshold was set that clearly distinguished the target from background. This threshold selected targets falling within a specific density range. All pixels lying within this density range were regarded by the computer as a target, and all other pixels were regarded as background. To improve the accuracy of the counts, a mean target size was determined so that the number of targets in a cluster of cells could be estimated. Care was taken throughout the analysis to ensure that lighting and background correction were constant for all sections analyzed within a given region. To ensure that our method of background correction was valid, we also analyzed the data by manually reading a region of the brain that did not contain signal and then subtracting this value from the values obtained by reading labeled cells. We obtained the same results with both methods of analysis (data not shown).

In the nBM, groups of three cells (designated a cell profile) were identified under high power $(40 \times)$ using bright-field microscopy. The number of silver grains overlying cach labcled ccll profilc was then counted under dark-field microscopy. Cells in the nBM were analyzed in this manner because it was difficult to find multiple cases in which silver grains of individually labeled cells did not overlap with the grains of neighboring labeled cells. The number of positively labeled cells was obtained from bilateral readings of five cell profiles from two sections for each animal.

In the HDB and VDB, cells were densely clustered together and it was not possible to assign grains to individually labeled cells; therefore, relative regional rather than cellular levels of trkA and ChAT mRNAs were quantified at $10 \times$ magnification in these areas. A target acceptance criterion was used in which the target area was defined as an area greater than the mean target size. Using this criterion, the densely clustered cells in the HDB and VDB were treated as clusters of smaller targets of a given size rather than as one large target. Data are presented as grains per region, and the locations of the regions selected for analysis are depicted in Figure 1 . The number of grains per region was obtained from bilateral readings from two sections for each animal.

Statistical analysis. Data are represented as mean \pm SEM. Data were analyzed by a two-way ANOVA to test for differences in trkA or ChAT mRNA levels among the intact, ovx, and ovx $+E$ groups in each of the three regions investigated. Post-hoc comparisons were made using a Fisher or Scheffe test.

\section{RESULTS}

To begin testing the possibility that neurotrophins are involved in mediating the trophic effects of estrogen on basal forebrain systems, the effects of estrogen on the expression of the $\mathrm{NGH}$ receptor trkA were examined. Representative low-power darkfield micrographs depicting the effects of short-term ovx and estrogen replacement on the relative levels of trkA mRNA in the $\mathrm{nBM}, \mathrm{HDB}$, and VDB are shown in Figure 2 and are graphically summarized in Figure 3. Ten days of estrogen deprivation after ovx resulted in significant decreases in trkA mRNA levels in two of the basal forebrain regions examined. TrkA mRNA levels were reduced by $34 \%$ in the $\mathrm{nBM}$ and by $56 \%$ in the HDB compared with intact animals. Three days of estrogen replacement restored trkA mRNA expression to a level comparable with intact animals. In contrast, ovx and estrogen replacement had no significant effects on trkA mRNA levels in the VDB.

ChAT expression has been shown to be sensitive to estrogen treatment in the basal forebrain (Luine et al., 1975, 1986; Luine and McEwen, 1983; Gibbs et al., 1994; Singh et al., 1994). Because this enzyme is critically involved in the biosynthesis of acetylcholine, changes in ChAT mRNA expression can be used as an indirect measurement of the functional status of cholinergic ncurons. To determine whether the decreased expression of trkA mRNA as a result of ovx was accompanied by changes in ChAT mRNA expression, the effects of ovx and estrogen replacement on ChAT mRNA levels were also examined. As reported previously by Gibbs et al. (1994), the pattern of distribution of ChAT mRNA-containing cells in the $\mathrm{nBM}, \mathrm{HDB}$, and VDB was similar to that observed for trkA mRNA (data not shown). The results of ovx and estrogen replacement on the relative levels of ChAT mRNA are summarized in Figure 4. Ovx resulted in significant decreases in the levels of ChAT mRNA in the same basal forebrain regions in which trkA mRNA was reduced (a decrease of 35 and $38 \%$ in the nBM and HDB, respectively). Similar to its effects on trkA expression, estrogen replacement was able to restore ChAT mRNA expression to the levels observed in intact animals. In addition, ovx and estrogen replacement failed to influence 


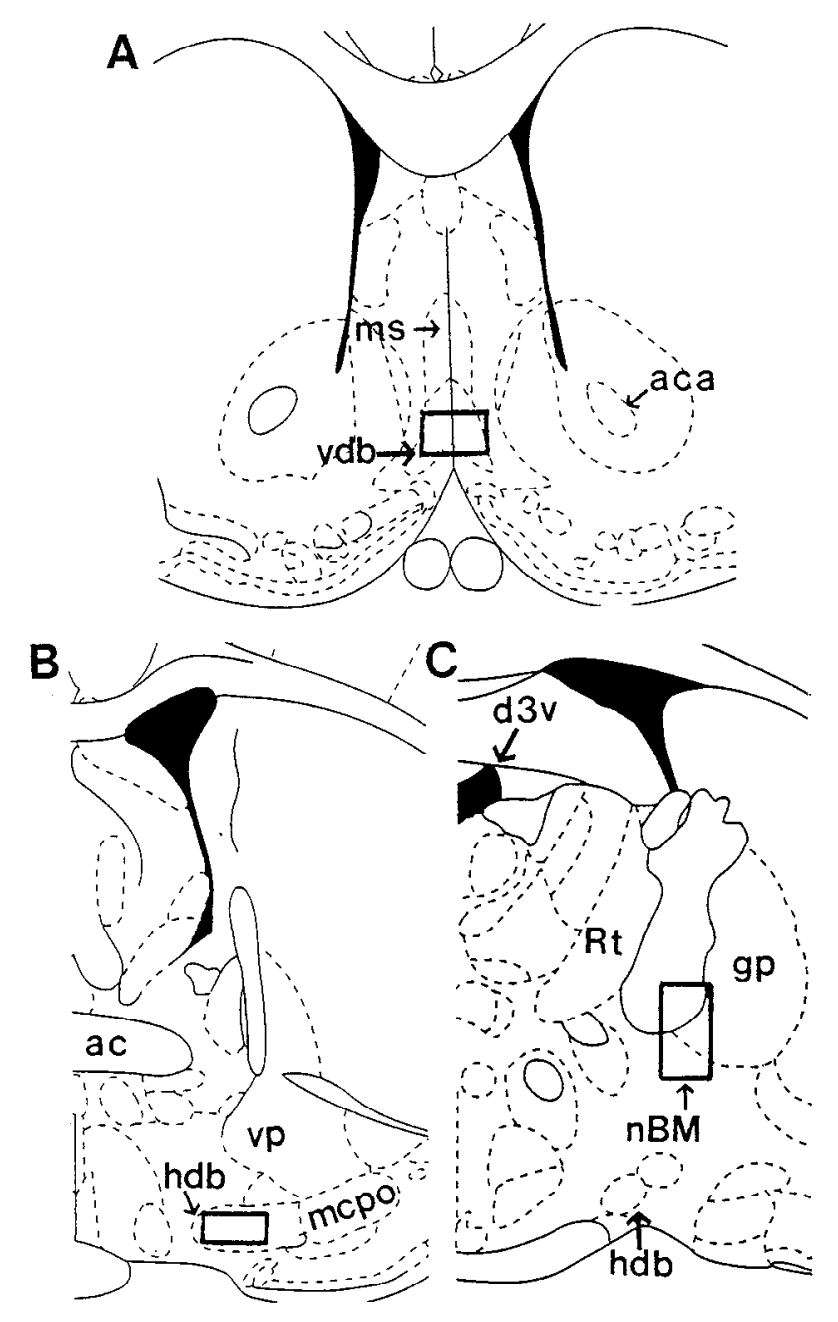

Figure 1. Schematic drawing depicting the regions in which trkA and ChAT hybridization signals were evaluated (boxed regions) in the vertical diagonal band $(A)$, horizontal diagonal band $(B)$, and nucleus basalis of Meynert $(C)$. $a c$, Anterior commissure; $a c a$, anterior commissure, anterior region; $d 3 v$, dorsal third ventricle; $g p$, globus pallidus; $h d b$, horizontal limb of the diagonal band of Broca; mcpo, magnocellular preoptic nucleus; $m s$, medial septum; $n B M$, nucleus basalis of Meynert; $R t$, reticular thalamic nucleus; $v d b$, vertical limb of the diagonal band of Broca; $v p$, ventral pallidum. Drawings are modified from Paxinos and Watson (1986).

ChAT mRNA levels in the VDB, further mirroring the effects of estrogen on trkA expression.

\section{DISCUSSION}

The data presented above suggest that withdrawal of circulating levels of ovarian steroids results in a reduction in trkA mRNA levels in specific basal forebrain cholinergic neurons. This decrease in trkA gene expression is accompanied by a decrease in ChAT gene expression, suggesting a possible decline in cholinergic function. A $3 \mathrm{~d}$ estrogen replacement regimen reverses these affects and restores trkA and ChAT mRNA levels to normal. These results are similar to those observed by Sohrabji et al. (1994b) in the rat DRG. This study demonstrated that the hormonal conditions existing at proestrus (high estrogen levels) upregulated trkA and $p 75$ receptor mRNA levels threefold compared with animals that had been ovariectomized ( $10 \mathrm{~d}$ ovx $)$. In addition, comparison of trkA gene expression in the DRG of ovx animals and of ovx animals treated with a single $10 \mu \mathrm{g}$ injection of estradiol benzoate demonstrated a twofold increase in trkA receptor mRNA levels $4 \mathrm{hr}$ after estrogen treatment and a threefold increase $52 \mathrm{hr}$ after injection. In contrast, p75 was transiently downregulated under these conditions. This differential regulation of trkA and p75 was also observed in vitro in PC12 cells (Sohrabji et al., 1994a). Singh et al. (1995) offer further support for the possible interaction between estrogen and neurotrophins. These investigators found that long-term estrogen deprivation (28 weeks ovx) resulted in significant reductions in BDNF mRNA levels in the cortex and hippocampus. Chronic administration of estrogen ( 28 weeks) was effective in elevating BDNF mRNA levels in the hippocampus but was without effect in the cortex, suggesting a regional specificity in the ability of ovarian steroids to influence the expression of BDNF. Similar studies on NGF expression revealed a $45 \%$ decline in the levels of its mRNA in the frontal cortex after ovx, which was partially reversed by administration of estrogen (Singh et al., 1993).

It is important to note that in our study, intact animals were not cycled before killing. Therefore, it is possible that the animals studied may have different endogenous estrogen levels. It has been reported recently by Gibbs (1995) that the relative levels of ChAT mRNA fluctuate during the course of the estrous cycle. Although no data are currently available concerning the relative levels of trkA during the estrous cycle, it seems likely that the levels of this mRNA will also fluctuate.

The molecular mechanisms by which estrogen may regulate trkA gene expression are currently unknown. The presence of a putative estrogen response element (ERE) in the 5'-flanking region of the trkA gene suggests that estrogen may directly regulate trkA gene transcription via the classical ligand-activated steroid receptor mechanism. Regulation of neurotrophin gene expression by this mechanism is not without precedent. Using gel-shift assays, Sohrabji et al. (1994c) found that nuclear protein extract from estrogen-treated MCF-7 cells resulted in a shift in the migration of the gene encoding BDNF. This shift was a result of the binding of the estrogen receptor-ligand complex to an EREcontaining fragment of the DNA, strongly suggesting that estrogen may regulate transcription of the BDNF gene. Alternatively, estrogen could regulate trkA gene expression by regulating the stability of the trkA mRNA. It has been known for some time that estrogen can regulate the turnover rates of some mRNAs. For example, estrogen is known to alter dramatically the stability of the vitellogenin mRNA, increasing the half-life of this message from 16 to $480 \mathrm{hr}$ (Brock and Shapiro, 1983). Alterations in mRNA stability as a means of regulating gene expression have been demonstrated previously in the neurotrophin family. For example, regulation of the NGF gene by okadaic acid is at least partially caused by a change in NGF mRNA stability (Pshenichkin and Wise, 1995). The abundance of a $140 \mathrm{kDa}$ protein that specifically binds an adenosine uridine (AU)-rich region of the $3^{\prime}$-UTR of the NGF mRNA increases after okadaic acid treatment in a time course consistent with increased stability of the NGF mRNA. Additional studies will be required to determine whether regulation of trkA gene expression by estrogen occurs at a transcriptional or post-transcriptional level.

Interestingly, not all studies indicate a positive correlation between estrogen and neurotrophin expression. Gibbs et al. (1994) examined the effects of estrogen replacement on trkA, NGF, and ChAT mRNA levels in the basal forebrain and hippocampal formation of ovx rats. In this study, estrogen replacement resulted in significant decrcases in the levels of NGF mRNA in the hippocampus and of trkA mRNA in the medial septum (MS) and 
A

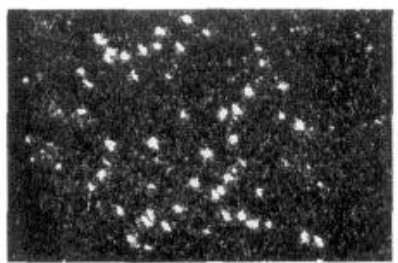

HDB

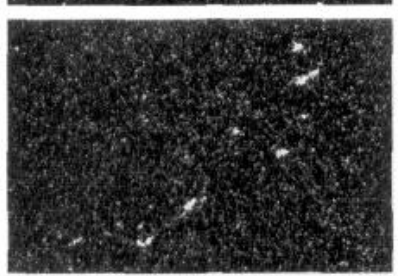

VDB

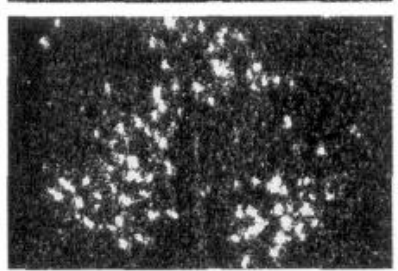

B
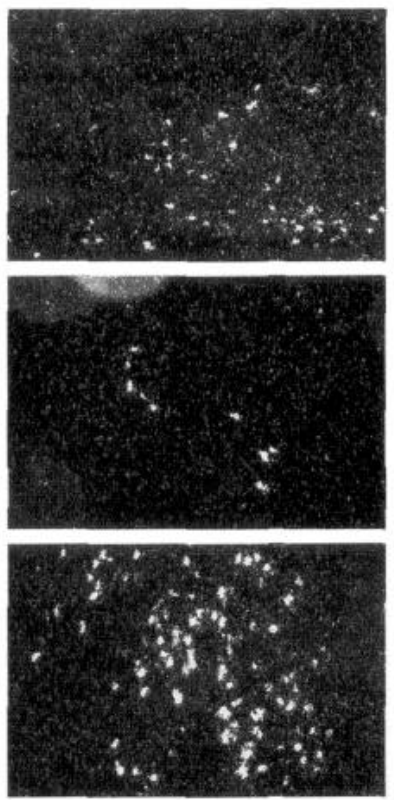

C
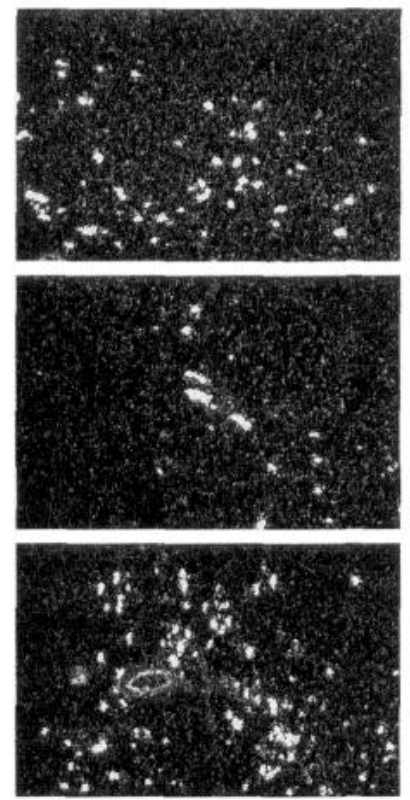

Figure 2. Representative dark-field photomicrographs $(10 \times$ magnification) showing the distribution of trkA mRNAcontaining cells (represented by clusters of silver grains overlying labeled cells) detected by in situ hybridization in the HDB and VDB of the nBM of intact $(A)$, ovariectomized $(B)$, and estrogenreplaced $(C)$ female rats.
nBM but not in the HDB. In contrast, estrogen replacement significantly increased the levels of ChAT mRNA in the nBM, in agreement with the present study, and also enhanced levels in the MS. However, in contrast to the present study, estrogen replacement failed to alter ChAT mRNA levels in the HDB. The investigators suggest that the time course of these actions indicates that estrogen may first exert a direct effect on ChAT and NGF expression, followed by an indirect effect on trkA expression. These results seem to contradict the effects of estrogen on trkA gene expression reported in this study. However, a difference in the dose and time course in which estrogen replacement was given could explain these conflicting results. Gibbs et al. (1994) observed a decrease in trkA mRNA expression in the nBM and MS when ovx rats were implanted for 2 weeks with estrogen- containing SILASTIC capsules. In our study, we observed an increase in trkA mRNA expression in the nBM and $\mathrm{HDB}$ when ovx rats were injected with $10 \mu \mathrm{g}$ of estrogen daily for $3 \mathrm{~d}$. Our method of estrogen replacement may have resulted in fluctuating levels of circulating estrogen throughout the time course of the estrogen treatment, which is less likely to have occurred with SILASTIC implants. However, Gibbs et al. (1994) failed to observe an increase in trkA mRNA in the nBM and HDB of ovx rats after $2 \mathrm{~d}$ of subcutaneous estrogen injections. It is possible that the duration of estrogen replacement in this case was not sufficient to observe this effect. Taken together, these data suggest that estrogen may produce a transient upregulation of trkA mRNA, followed by a downregulation after more prolonged treatment, as reported by Gibbs et al. (1994).
$\mathrm{nBM}$

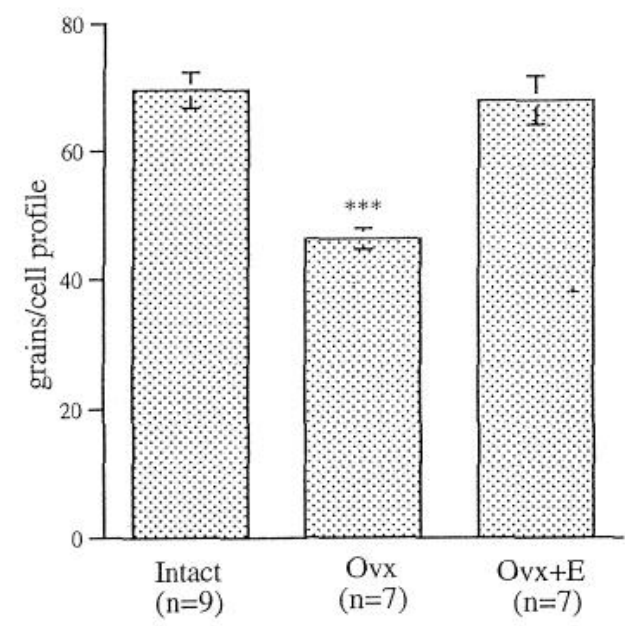

HDB

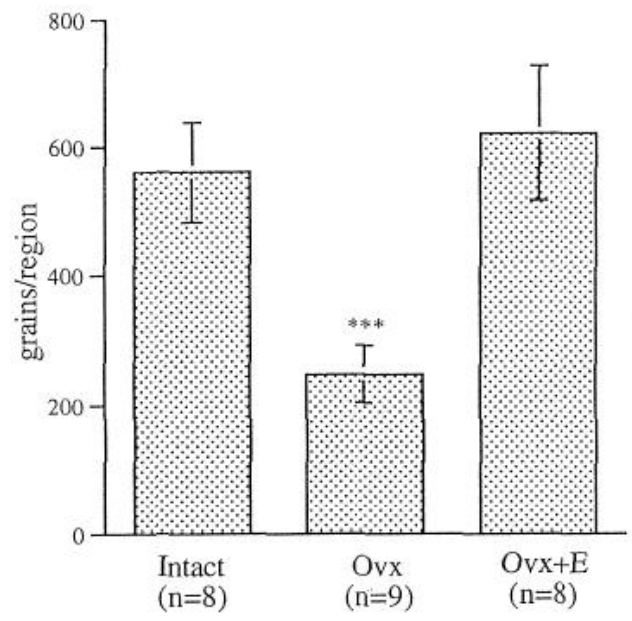



Figure 3. Graphical representation of the effects of ovariectomy $(O v x)$ and estrogen replacement $(O v x+E)$ on trkA mRNA levels in the $n B M$ and the $H D B$ and $V D B$ detected by in situ hybridization. The specificity of the trkA riboprobe used in this assay was verified previously by hybridization with a

${ }^{35}$ S-labeled sense control riboprobe, which failed to demonstrate labeling (data not shown). Each bar represents the mean \pm SEM of seven to nine animals. The hybridization signal for each animal was obtained from bilateral readings from two sections; therefore, the value for each animal is an average of four readings. Analysis of cells in the nBM was performed at $40 \times$ magnification, and analysis of cells in the HDB and VDB was performed at $10 \times$ magnification (see Materials and Methods). ${ }^{* * *} p<0.001$ versus Intact or $O v x+E$. 
$\mathrm{nBM}$



HDB

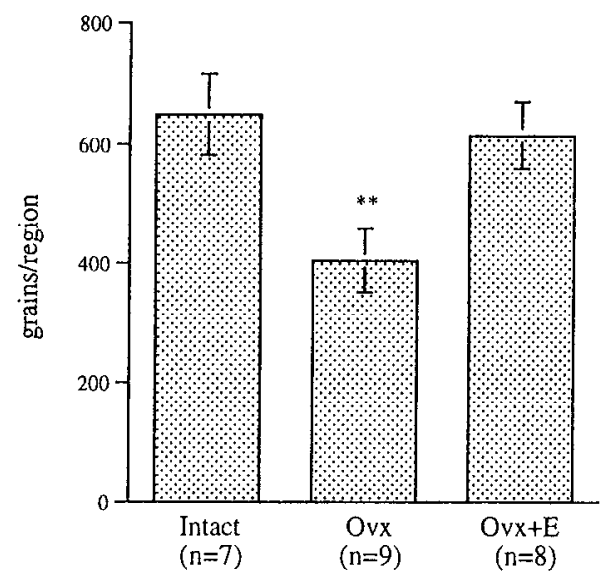

VDB

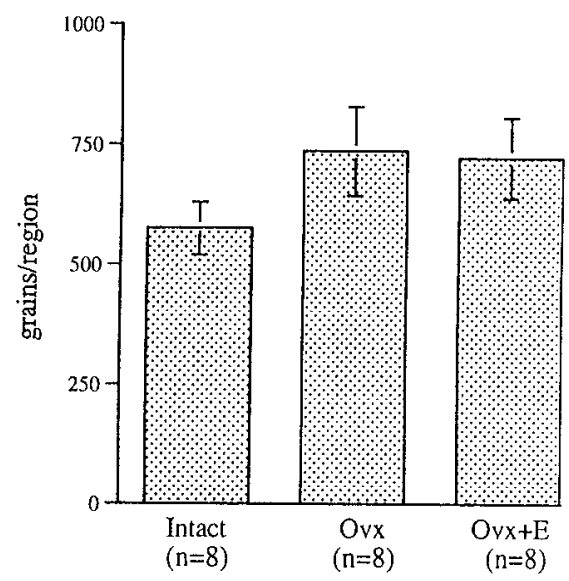

Figure 4. Graphical representation of the effects of ovariectomy $(O v x)$ and estrogen replacement $(O v x+E)$ on ChAT mRNA levels in the $n B M$ and the $H D B$ and $V D B$ detected by in situ hybridization. The specificity of the ChAT riboprobe used in this assay was verificd previously by hybridization with ${ }^{35}$ S-labeled sense control riboprobe, which failed to demonstrate labeling (data not shown). Each bar represents the mean \pm SEM of seven to nine animals. The hybridization signal for each animal was obtained from bilateral readings from two sections; therefore, the value for each animal is an average of four readings. ${ }^{* * *} p<0.001$ versus Intact or $O v x+E$; ${ }^{* *} p<0.01$ versus Intact or $O v x+E$.

Aging in both females and males results in a decline in the secretion of estrogen or of androgens that can be aromatized to estrogen. Given the present data, a decrease in the trophic influence of circulating estrogen could be partially responsible for the degeneration of basal forebrain cholinergic neurons and the decline in cognitive function that is associated with aging and with certain neurodegenerative diseases. This possibility is supported by recent reports indicating that postmenopausal women who receive estrogen replacement therapy exhibit a lower incidence of Alzheimer's disease than women receiving no treatment (Paganini-Hill and Henderson, 1994). The ability of estrogen to upregulate the neurotrophins and their receptors could potentially underlie these trophic effects. NGF increases ChAT mRNA levels, enhances ChAT activity, and increases ACh release (Cavicchioli et al., 1991; Lorenzi et al., 1992; Rylett et al., 1993). Therefore, an increase in trkA expression in response to estrogen could result in an enhancement of NGF signaling through the trkA receptor, resulting in elevated ChAT mRNA levels and ChAT activity and an enhancement of cholinergic function. The fact that estrogen can also increase the expression of NGF and BDNF makes it an even more attractive therapeutic agent because there is evidence suggesting that neurotrophic factors may act synergistically when administered in combination. It is important to note from the study by Gibbs et al. (1994) that estrogen may have very different effects on neurotrophin gene expression depending on the dose and duration of treatment. However, in postmenopausal estrogen-replacement therapy, estrogen is usually administered daily as an oral supplement. Therefore, the daily subcutaneous injections of estrogen used in our study may more closely mimic estrogen replacement therapy in humans.

In conclusion, these data show that estrogen can significantly enhance trkA mRNA expression in specific regions of the basal forebrain. The data also confirm previous reports on the effects of estrogen on ChAT mRNA levels in the nBM, but differ with respect to the effects of estrogen on ChAT mRNA expression in other cholinergic cell populations. These studies support the hypothesis that the trophic effects of estrogen on cholinergic systems may be mediated in part via the signaling of neurotrophins through their receptors. In addition, the data support the need for further investigation into the use of estrogen as a therapeutic tool for treatment of neurodegenerative diseases such as Alzheimer's disease.

\section{REFERENCES}

Brock ML, Shapiro DJ (1983) Estrogen stabilizes vitellogenin mRNA against cytoplasmic degradation. Cell 34:207-214.

Cavicchioli L, Flanigan TP, Dickson JG, Vantini G, Dal Toso R, Fusco M, Walsh FS, Leon A (1991) Choline acetyltransferase messenger RNA expression in developing and adult rat brain: regulation by nerve growth factor. Brain Res Mol Brain Res 9:319-325.

Dekker AJ, Gage FH, Thal LJ (1992) Delayed treatment with nerve growth factor improves acquisition of a spatial task in rats with lesions of the nucleus basalis magnocellularis: evaluation of the involvement of different neurotransmitter systems. Neuroscience 48:111-119.

Decker MW, McGaugh JL (1991) The role of interactions between the cholinergic system and other neuromodulatory systems in learning and memory. Synapse 7:151-168.

Fischer W, Wictorin K, Bjorklund A, Williams LR, Varon S, Gage FH (1987) Amelioration of cholinergic neuron atrophy and spatial memory impairment in aged rats by nerve growth factor. Nature 329:65-68.

Gibbs RB (1995) Changes in the expression of choline acetyltransferase (ChAT) mRNA across the estrus cycle: effects of estrogen and progesterone. Soc Neurosci Abstr 21:228.6.

Gibbs RB, Wu D, Hersh LB, Pfaff DW (1994) Effects of estrogen replacement on the relative levels of choline acetyltransferase, trkA, and nerve growth factor messenger RNAs in the basal forebrain and hippocampal formation of adult rats. Exp Neurol 129:70-80.

Ishii K, Oda Y, Ichikawa T, Dcguchi T (1990) Complementary DNAs for choline acetyltransferase from spinal cords of rat and mouse: nucleotide sequences, expression in mammalian cells, and in situ hybridization. Brain Res Mol Brain Res 7:151-159.

Lapchak PA, Araujo DM, Hefti F (1993) Regulation of hippocampal muscarinic receptor function by chronic nerve growth factor treatment in adult rats with fimbrial transections. Neuroscience 53:379-394.

Lorenzi MV, Knusel B, Hefti F, Strauss WL (1992) Nerve growth factor regulation of choline acetyltransferase gene expression in rat embryo basal forebrain cultures. Neurosci Lett 140:185-188.

Luine VN, McEwen BS (1983) Sex differences in cholinergic enzymes of diagonal band nuclei in the rat preoptic area. Neuroendocrinology $36: 475-482$.

Luine VN, Khylchevskaya RI, McEwen BS (1975) Effect of gonadal steroids on activities of monoamine oxidase and choline acetylase in rat brain. Brain Res 86:293-306. 
Luine VN, Renner KJ, Heady S, Jones KJ (1986) Age and sex-dependent decreases in ChAT in basal forebrain nuclei. Neurobiol Aging 7:193-198.

Paganini-Hill A, Henderson VW (1994) Estrogen deficiency and risk of Alzheimer's disease in women. Am J Epidemiol 140:256-261.

Paxinos G, Watson C (1986) The rat brain in stereotaxic coordinates. Sydney: Academic.

Pshenichkin SP, Wise BC (1995) Okadaic acid increases nerve growth factor secretion, mRNA stability, and gene transcription in primary cultures of cortical astrocytes. J Biol Chem 270:5994-5999.

Rylett RJ, Goddard S, Schmidt BM, Williams LR (1993) Acetylcholine synthesis and release following continuous intracerebral administration of NGF in adult and aged Fischer-344 rats. $J$ Neurosci 13:3956-3963.

Shughrue PJ, Bushnell CD, Dorsa DM (1992) Estrogen receptor messenger ribonucleic acid in female rat brain during the estrous cycle: a comparison with ovariectomized females and intact males. Endocrinology 131:381-388.

Singh M, Meyer EM, Huang FS, Millard WJ, Simpkins JW (1993) Ovariectomy reduces ChAT activity and NGF mRNA levels in the frontal cortex and hippocampus of the female Sprague-Dawley rat. Soc Neurosci Abstr 19:514.11.
Singh M, Meyer EM, Millard WJ, Simpkins JW (1994) Ovarian steroid deprivation results in a reversible learning impairment and compromised cholinergic function in female Sprague-Dawley rats. Brain Res 644:305-312.

Singh M, Meyer EM, Simpkins JW (1995) The effect of ovariectomy and estradiol replacement on brain-derived neurotrophic factor messenger ribonucleic acid expression in cortical and hippocampal brain regions of female Sprague-Dawley rats. Endocrinology 136: 2320-2324.

Sohrabji F, Greene LA, Miranda RC, Toran Allerand CD (1994a) Reciprocal regulation of estrogen and NGF receptors by their ligands in PC12 cells. J Neurobiol 25:974-988.

Sohrabji F, Miranda RC, Toran Allerand CD (1994b) Estrogen differentially regulates estrogen and nerve growth factor receptor mRNAs in adult sensory neurons. J Neurosci 14:459-471.

Sohrabji F, Miranda RC, Toran-Allerand CD (1994c) Identification of a potential estrogen response element in the gene coding for brain derived neurotrophic factor (BDNF). Soc Neurosci Abstr 20:536.12.

Toran Allerand CD, Miranda RC, Bentham WD, Sohrabji F, Brown TJ, Hochberg RB, MacLusky NJ (1992) Estrogen receptors colocalize with low-affinity nerve growth factor receptors in cholinergic neurons of the basal forebrain. Proc Natl Acad Sci USA 89:46684672 . 